
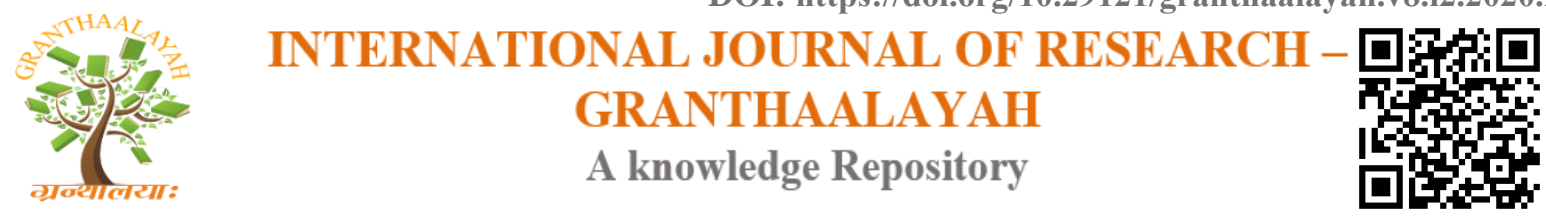

Science

\title{
SURVEY ON SMALL RUMINANT PRODUCTION AGAINST PESTE DES PETITS RUMINANT IN MOYAMBA AND KAILAHUN DISTRICTS, SIERRA LEONE
}

\author{
Conteh, AM. ${ }^{* 1}$, Kallon, NM. ${ }^{2}$, Jojo, DH. ${ }^{3}$, Sesay, AR. ${ }^{4}$, Bundu, WT ${ }^{5}$ \\ *1,2, 3,4,5 Animal Science Department, Njala University, Sierra Leone
}

\begin{abstract}
Goats and sheep production which significantly contributes to improving nutritional status, economic growth and socio-cultural practices in the rural settings of Sierra Leone are faced with several challenges. The survey on Peste des Petits Ruminants Virus (PPRV) was carried out to investigate the: current status of small ruminant production, and the presence of antibodies against PPRV. Information was obtained through Focus Group Discussion in the respondents' local dialects from 150 participants. From the results obtained, 58.7\% and 41.7\% of the respondents were male and female while $77.3 \%$ and $22.7 \%$ were married and single respectively. $53.3 \%$ of the respondents never illiterate while $46.7 \%$ have some basic education. The main reasons for keeping goats and sheep were for traditional, economic, religious and food. Continuous disease outbreaks; high mortality; poor animal healthcare and extension services, lack of credit facility, theft, and poor marketing facility. Pestes des petits Ruminant, mange, Respiratory infection, and diarrhea were the main diseases affecting goats and sheep. A total of 356 serum samples from goats (264) and sheep (92) were collected in both districts and analyzed using the competitive ELISA kit for the detection of antibodies against PPRV. The result revealed an overall prevalence of $62.1 \%$ antibodies [goats, 73.1\%, (193/264) and sheep, 30.4\%, (28/92)]. Young goats $(65.9 \%)$, and sheep (34.7\%) showed the highest seropositivity of PPRV followed by adult males and females. There is a need to improve traditional practices of small ruminant production by designing disease control programs to ensure the full participation of the veterinary, animal husbandry and extension services for a good output.
\end{abstract}

Keywords: Antibodies; Constraint; Contributions of Small Ruminants; Management-Practices; Seroprevalence; Sierra Leone.

Cite This Article: Conteh, AM., Kallon, NM., Jojo, DH., Sesay, AR., and Bundu, WT. (2020). "SURVEY ON SMALL RUMINANT PRODUCTION AGAINST PESTE DES PETITS RUMINANT IN MOYAMBA AND KAILAHUN DISTRICTS, SIERRA LEONE." International Journal of Research - Granthaalayah, 8(2), 243-253. 


\section{Introduction}

Small ruminants (sheep and goats) production (SMP) is significant and common practices in agriculture that strengthen livelihood, economic status, socio-cultural/religious practices in both developed and developing countries. Goats and sheep are among the largest domesticated and culturally owned animals with little or no taboos in most countries. Global statistics of goat (861.9) and sheep (1078.2) million depicted that $93.5 \%$ of goats and $68.7 \%$ of sheep are found in developing continents (Africa and Asia) [1]. These animals are managed under different management systems (intensive, semi-intensive and extensive) and environments for multiple benefits. Small ruminant production performs diverse functions that vary from individual to individual and from one setting to another. In Africa and other low-income continents, the contributions of small ruminants to food security, poverty alleviation, gender equality, sociocultural values, economic empowerment, reducing unemployment and malnutritional problems are well documented $[2,3,4,5]$.

In Sierra Leone, SMP is the second-largest component in agriculture that is mainly handled by the poor with significant contributing at both national and rural levels. Current statistics of small ruminants' population in the country disclosed that 814,269 and 574,706 are goats and sheep respectively [6]. The major system of rearing small ruminants (SRs) is the free-range system especially in the dry season due to feed scarcity. In the rainy season due to crop production, animals are either tethered or confined to avoid conflict with crop growers while in urban areas most farmers practiced intensive systems. The potential contributions of SRs (domestic and nondomestic functions) are key particularly in the rural areas where it brings cash and food for farmers and promotes socio-cultural and religious practices. SRs are well known for their adaptive natural physiognomies enabling them to survive under poor management conditions. Amid all these unique characteristics and valuable contributions fulfilled, small ruminant production is continuously threatened by multiple constraints including diseases, feed scarcity, poor management, lack of knowledge and technical support. The main production constraint farmers encounter in goat and sheep production is Peste des Petits Ruminants (PPR) disease. PPR is an economically viral infection that disturbs the livelihood and income-earning level of farmers, consumers, and traders. It is a severe contagious and fatal disease with many related clinical signs affecting a wide range of ruminants (domestic and wild) [7,8]. Although various species of animals are affected, goats and sheep are the most susceptible regardless of age and sex. The virus belongs to the genus Morbillivirus in the family Paramyxoviridae with genetic similarity to other members of Morbillivirus (Rinderpest virus, canine distemper, measle virus, cetacean Morbillivifus, feline Morbillivirus) $[9,10]$. It is characterized by nasal and ocular discharge, difficult breathing due to stuffy nose, coughing, foul-smelling diarrhea, pneumonia, high fever $\left(38-40^{\circ} \mathrm{C}\right)$, lesion (mouth and nasal) and sudden death [9,11]. Since the discovery of the PPRV in West Africa (Nigeria, 1942), the virus has been reported throughout Africa and beyond with high mortality and morbidity rate in endemic areas $[12,13]$. Depending on the severity of the outbreak, mortality and morbidity rate can reach 80-100\% among unprotected indigenous breeds [9]. The impact of PPR disease on humans and animals has not been clearly understood due to limited research and lack of appropriate diagnostic capacity in many developing countries leading to gross underreporting. 
Sierra Leone bordering with the Atlantic Ocean, Liberia and Guinea has been severely hit by PPR outbreaks for several decades. The disease was first thought to be introduced in the country during a restocking program after the ten years of civil war that destroyed approximately $90 \%$ of the livestock population. The majority of the livestock in the country have their route from neighboring countries (Guinea, Liberia, and Mali) which could have been a possible source of the disease. Since the detection of PPRV in 2009 at the Central Veterinary Laboratory at Makeni, Northern Sierra Leone, there has not been any confirmatory laboratory report until recent (2018). Farmers have lost thousands of goats and sheep due to weak veterinary services, lack of diagnostic capacity, inadequate biosecurity measures and poor implementation of livestock policy. PPR is endemic and catastrophic especially in areas where the animals are less care for and are extensively managed. PPR is assumed to be poorly understood in most parts of the country among farmers as most conditions are judged based on related clinical signs and frequent death. Therefore, this study is conducted to 1, provide information on the current status of small ruminants' production in selected districts with respect to 1 , reasons for goats and sheep. 2, challenges. 3 , the prevalence of PPRV antibodies in goats and sheep.

\section{Materials and Method}

The study was conducted in the Kailahun district (KD) and Moyamba district (MD) located in the Eastern and Southern parts of Sierra Leone. Kailahun district is bordered with the Republic of Guinea and Kono district in the north, Kenema district in the west, and the Republic of Liberia to the east. Kailahun has mixed vegetation of forest, secondary farm-bush, and savannah as described by [14]. The annual rainfall in the district is 2,001 to 3,000 $\mathrm{mm}$ with 10 months. Moyamba District is the largest district in the south-western part of Sierra Leone with a total surface area of 6,902 $\mathrm{Km}$. In the west, it is bordered with the Atlantic Ocean; Bo in the east; Bonthe in the south; Port Loko and Tonkolili districts in the north. The mean annual rainfall varies from 125 to $250 \mathrm{~mm}$. The main vegetation includes secondary farm-bush, savannah, inland valley swamp, mangrove, patches of primary forest, and many water bodies including lakes. Kailahun and Moyamba districts have a population of 526,379 and 318,588 with a mixed economy (small scale mining, agriculture, trading, and formal job) [6]. $75.8 \%$ and $77.9 \%$ of the population in Kailahun and Moyamba districts are engaged in animal husbandry practices while $95.4 \%$ and $87.5 \%$ practiced crop production respectively. Kailahun has approximately 75,090 and 37,173 goats and sheep while Moyamba has 42,286 and 15,206 goats and sheep respectively [6].

\section{Sampling Methodology}

Two villages in each district (Moyamba district: Nyadehun and Ngeiya, Kailahun district: Buedu and Pioto) with a large number of goats and sheep populations were selected for sampling. Samples were collected from both sick and seemingly healthy animals regardless of their ages and status (pregnant, lactating, young or old). 66 goats and 23 sheep were sampled per village resulting in a total blood sample of 132 (goats) and 92 (sheep) per district. Overall, 356 serum samples were collected during the study across the two districts. Two milliliters $(2 \mathrm{ml})$ of whole blood was collected per animal using a $5 \mathrm{ml}$ syringe and 23 -gauge needle and dispensed in a well-labeled plane glass tube (with no anticoagulant). The blood collected from the jugular vein was allowed to stand for 30 minutes at room temperature (RT) and centrifuge for 10 minutes for proper 
harvesting of the serum and stored at $-20^{\circ} \mathrm{C}$ before taken into the laboratory for diagnosis (antibody detection).

Quantitative data were collected in all four villages through Focus Group Discussion (FGD). FGDs were held in each of the four villages with small ruminant farmers for 1 hour forty-five minutes starting at 9:00 am. Key stakeholders per village were visited for their approval and to help organize the FGD. Date and time were unanimously fixed with a constant reminder and participants were informed before the proposed date. Each FGD comprises of 33 participants above the ages of 20 years.

The discussion started by observing religious ethics followed by self-introduction. The purpose of the FGD was explained by one of the research scientists in the local dialect (Mende, Temne, and Krio) and the expectations from the participants were made clear. Subjects like farmers' biodata, type of animal species rear, number of animals own per farmer, reasons for rearing, challenges encountered, disease conditions, possible source, occurrence season, duration per community, mortality rate, clinical manifestations, mode of transmission, and control measures were discussed. With consent from the participating communities and respondents, electronic device was used to record all the discussions and key points written down.

\section{Testing for PPR Antibodies}

All the sera samples collected were tested for PPR antibodies using a competitive Enzyme-Linked Immunosorbent Assay (cELISA) kit. The kit and its contents were brought out to RT as instructed by the manufacturer. The protocol was strictly followed as stated in the insert. To avoid differences incubation period, 28ul of the samples were dispensed into an uncoated 96 micro-well plates and transferred $(25 \mathrm{ul})$ with a multi-channel pipette into the coated plates after adding $25 \mathrm{ul}$ of dilution buffer 13 to each well followed by the controls. The plates were incubated for 45 minutes at $37^{\circ} \mathrm{C}$ and washed three times using an ELISA plate washer. Conjugate was prepared and added (100ul) followed by 30 minutes incubation at $37^{\circ} \mathrm{C}$, washed thrice again and incubate in the dark after adding the substrate solution for 15 minutes. The reaction was stopped (using 100ul stop solution per well) and the Optical Densities (OD) were read at 450nm using the detect ELISA machine.

\section{Data Analysis}

The controls were validated and used in the interpretation of the result following the manufacturer's instruction. Samples were considered positive if the Percentage Inhibition (PI) of the OD values were greater than $50 \%$ or negative if the PI is less than $45 \%$ otherwise retest, although no sample was retested. The data generated from the household survey questionnaire as well as the result of the analysis were analyzed using the Statistical Package for Social Scientist (SPSS) version 23.0. Findings were expressed in frequencies, percentages, and averages and presented in a table, figure and graph forms for simple interpretation and understanding. 


\section{Result and Discussion}

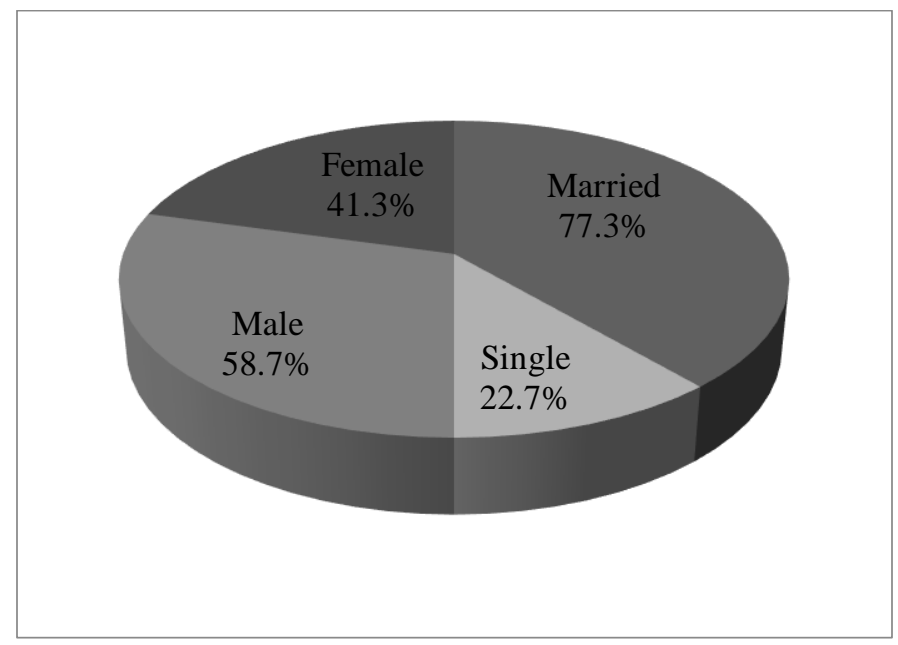

Figure 1: Gender and marital status of farmers

According to the FGDs (fig 1), a majority (58.7\%) of the respondents were men while $41.3 \%$ were women, $77.3 \%$ were married while $22.7 \%$ were single. Due to the household burden men carry as breadwinners followed by social lifestyle, small ruminant production is being spotted as feasible opportunities to addressing these needs. In table 1, 46.7\% (KD) and 34.7\% (MD) of the respondents can read and write while 53.3\%(KD) and $65.3 \%$ (MD) have no formal education. Different types of livestock species were kept under various systems of management. Local poultry accounted for the largest livestock reared followed by goat, sheep, and swine. The average number of livestock in $\mathrm{MD}$ (7.9) was greater than that recorded for $\mathrm{KD}$ (5.7).

On average, more farmers in $\mathrm{KD}$ (6.3) have many years of rearing experience compared to those in the MD (5.1). In the study period, $86.7 \%$ and $63.3 \%$ of the farmers raised their animals under the traditional management system, $56.0 \%$, and $68.0 \%$ practice semi-intensive system while only $6.7 \%$ and $10.7 \%$ used the intensive management system in Kailahun and Moyamba districts respectively. The reason behind the adoption of the traditional management system in the studied areas was its appropriateness in their daily lifestyle, level of education and awareness, and economic status. SMP in the study areas is mainly driven by cultural, feeding, social, and economic demands. Due to the large number of Muslims who observed Islamic traditions in the study areas, religious purpose was listed as the principal motive for keeping sheep although other benefits (economic, traditional and consumption) were mentioned. The level of demand for goat and sheep among the various tribes differ because of religious, economic, cultural and food diversities. Unlike sheep, goats are traditionally demanding.

Table 1: Farmers demographic status, livestock holding, management type, the purpose of keeping goat and sheep

\begin{tabular}{|l|c|c|}
\hline Variables & Kailahun $(\mathbf{n o}=\mathbf{7 5})$ & Moyamba $(\mathbf{n o}=\mathbf{7 5})$ \\
\hline Education (\%) & 46.7 & 34.7 \\
\hline Read and write & 53.3 & 65.3 \\
\hline No reading or writing ability & \multicolumn{2}{|l|}{} \\
\hline Livestock species rear (\%)
\end{tabular}




\begin{tabular}{|l|c|c|}
\hline Poultry & 93.3 & 73.3 \\
\hline Goat & 81.3 & 72.2 \\
\hline Sheep & 25.3 & 33.3 \\
\hline Swine & 2.7 & 0 \\
\hline Live animals (average) & 7.9 & 5.7 \\
\hline Rearing experience (average) & 5.1 & 6.3 \\
\hline Management system (\%) & \multicolumn{2}{|c|}{} \\
\hline Traditional (dry season) & 86.7 & 63.3 \\
\hline Semi-intensive (raining season) & 56 & 68 \\
\hline Intensive (annually) & 6.7 & 10.7 \\
\hline Reason for keeping goat (\%) & \multicolumn{2}{|c|}{} \\
\hline Income & 50.7 & 40 \\
\hline Traditional & 92 & 78.7 \\
\hline Eating & 70.7 & 27.8 \\
\hline Religion & 33.3 & 66.7 \\
\hline Reason for keeping sheep (\%) & 79.7 & 32 \\
\hline Income & 25.3 & 9.3 \\
\hline Traditional & 12 & 97.3 \\
\hline Food & 100 & \multicolumn{2}{|c|}{} \\
\hline Religion & \multicolumn{2}{|c|}{} \\
\hline
\end{tabular}

Although farmers occasionally sell goats for income generation, they are purposely meant for cultural reasons in Moyamba (96\%) and Kailahun (92\%) districts. $78.7 \%$ of the farmers in KD rear goats for consumption purposes compared to those in Moyamba district (70.7\%) while 50.7\% and $33.3 \%$ of the farmers in MD rear goats for economic and religious benefits.

The information in table 2 depicted that goat and sheep production is experiencing serious challenges that negatively impact production which therefore needs immediate interventions. In MD disease/parasite, high mortality, neighbor conflict, poor extension services, lack of credit facility, rampant stealing, feed shortage, poor market system, and inadequate housing facility were the major challenges reported. High mortality rate especially in young animals, weak extension services, poor market system, lack of modern treatment and credit facility, feed scarcity, poor housing, theft, and neighbor conflict were the main challenges reported in KD which is in agreement with the reports of $[15,16]$.

Table 2: Challenges affected the production of goats and sheep in Moyamba and Kailahun

\begin{tabular}{|l|c|c|c|c|}
\hline \multirow{2}{*}{ Variables } & \multicolumn{2}{|c|}{ Moyamba District } & \multicolumn{2}{c|}{ Kailahun District } \\
\cline { 2 - 5 } & Frequency & Percentage & Frequency & Percentage \\
\hline Disease/parasite & 74 & 98.7 & 69 & 92 \\
\hline Feed scarcity & 43 & 57.3 & 32 & 42.7 \\
\hline High mortality & 68 & 90.7 & 71 & 94.7 \\
\hline Lack of adequate shelter & 24 & 32 & 23 & 40 \\
\hline Poor treatment & 65 & 86.7 & 60 & 80 \\
\hline Theft & 45 & 60 & 25 & 33.3 \\
\hline Poor marketing system & 41 & 54.7 & 61 & 81.3 \\
\hline Ineffective extension services & 51 & 68 & 70 & 93.3 \\
\hline
\end{tabular}




\begin{tabular}{|l|c|c|c|c|}
\hline Neighbor conflict & 66 & 88 & 21 & 28 \\
\hline No credit or loan facility & 47 & 62.7 & 57 & 76 \\
\hline
\end{tabular}

In fig 2, nine diseases were listed by farmers when asked to identify common diseases of small ruminants. The main diseases identified in MD were PPR and mange while PPR, respiratory infection and mange were severe in Kailahun district. Other diseases or conditions like diarrhea, parasite, bloat, foot rot, and retained placenta were also reported which is in-line with [17] study. Uncontrolled and introduction of animals, poor handling of infected carcasses, contact between infected and healthy animals, poor management practices were identified as ways animals contract diseases. Early release of animals for grazing, toxic plants, poisons, oiled or salted polythene bags, fomites, and pets (carnivores) were named as additional causes for, bloat, and abortion. Although certain diseases were reported throughout the year, severe cases were noticed during the rainy season. Diseases like PPR, diarrhea, and RI lasted for a few weeks in a community while mange, footrot and parasitic infection can last up to a year or more in some communities.

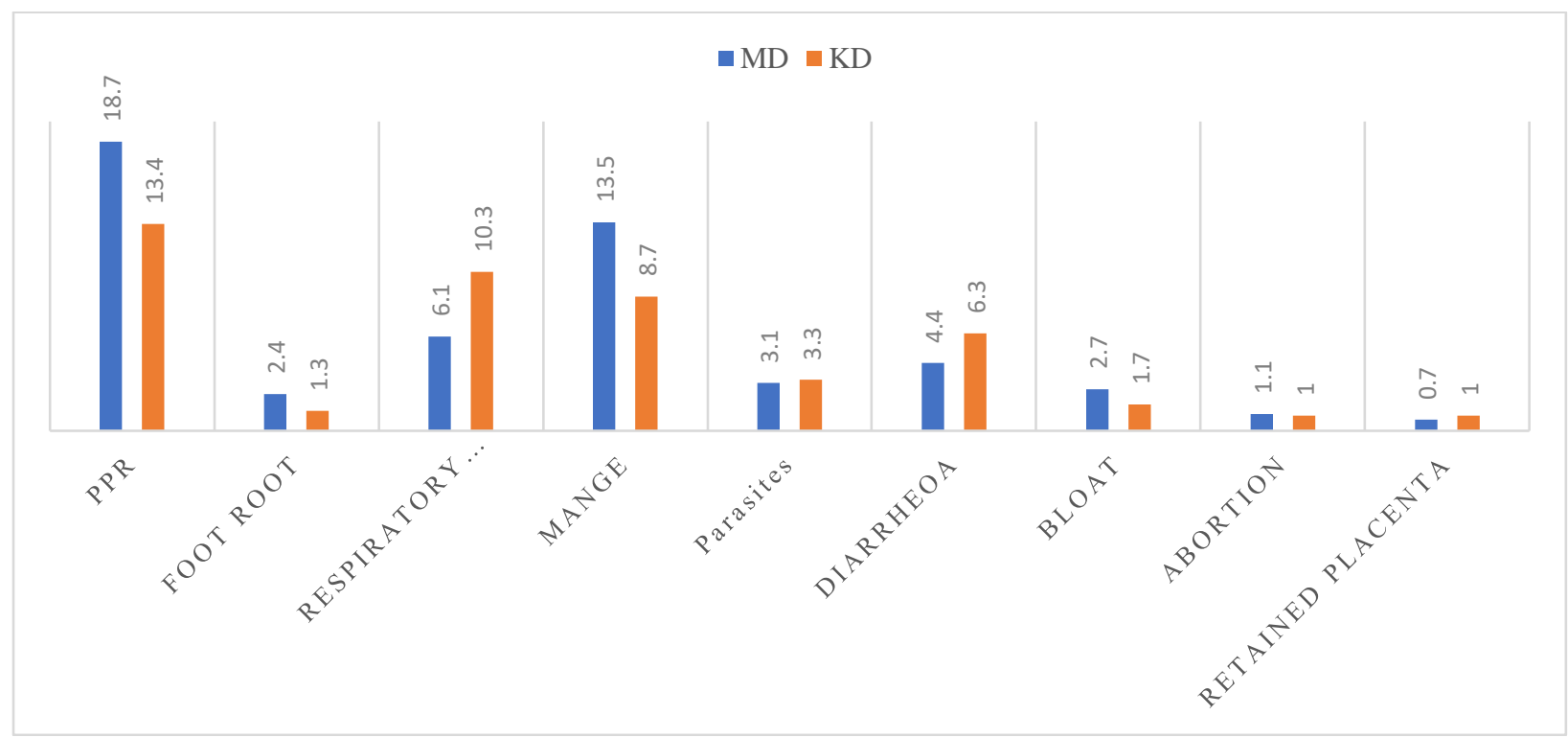

Figure 2: Death recorded and their causes

Symptoms like discharges (eye, nose mouth), high fever, diarrhea, hemorrhage, overgrown and damaged hoof, lameness, lesion between hoofs, kneel feeding, labored breathing, coughing, sneezing, coat damage, intense irritation and scratching, rubbing, restlessness, skin damage, dehydration, distended belly, lack of appetite, dyspnea, anemia, loss of weight, and blindness were associated with the abovementioned diseases which is in-line with $[9,18]$ reports. Transmission to healthy animals was through feces, body discharge, sharing shelter, feeding, and drinking points which is in agreement with the mode of transmission described by [19]. This was aided by direct contact between healthy and unhealthy, the introduction of new animals, uncontrolled movement of animals and improper handling of dead infected animals. Diseases were mainly controlled using traditional knowledge and skills by using herbs, antibiotics and anti-parasitic drugs followed by good management practices. The conventional method in the control, prevention, and eradication of diseases (veterinary services) is limited or lacking while farmers' knowledge and practices are inadequate to implement effective disease management at the rural level. 


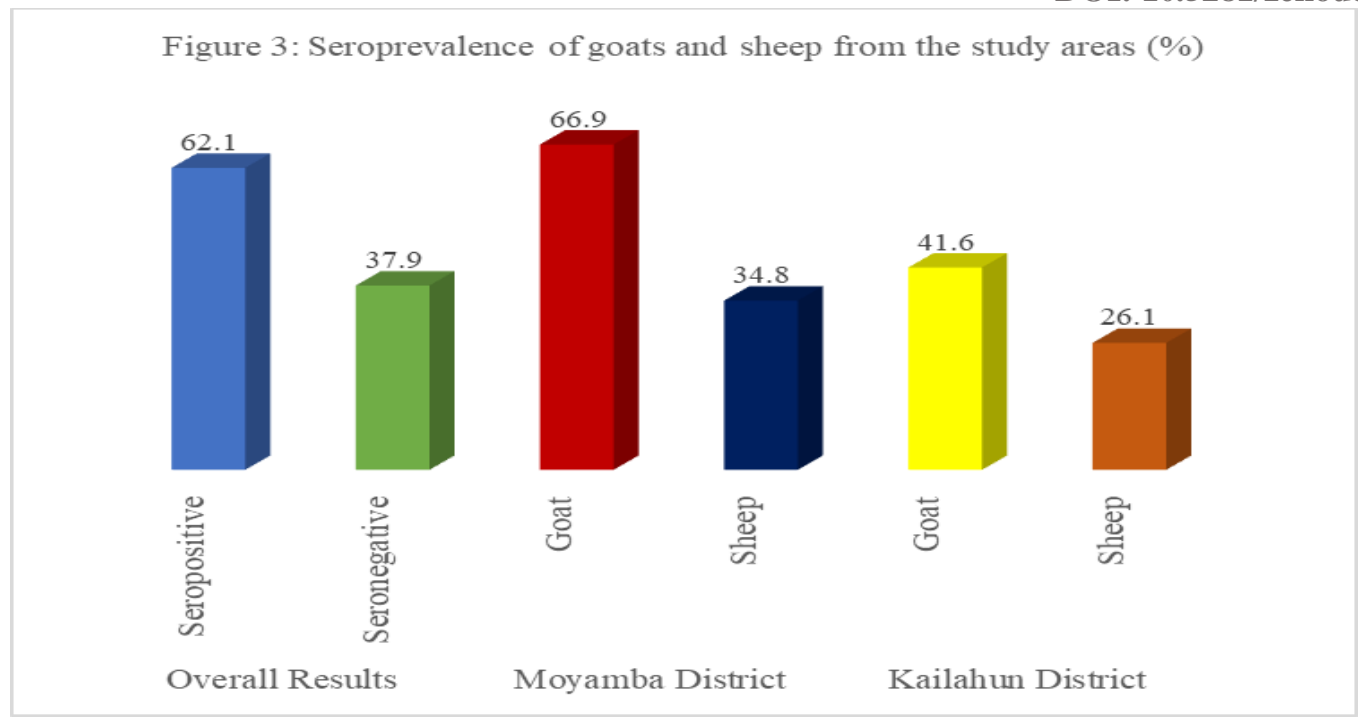

The overall seroprevalence of PPRV antibodies detection for 356 serum samples collected in the two districts revealed that $62.1 \%$ of goats and sheep were positive while $37.9 \%$ did not show any antibody (fig 3). In MD, 66.9\% (178) and 34.8\% (46) of the SRs which showed positive for PPR disease were goats and sheep while in KD, 41.6\% (178) and $26.1 \%$ (46) of the samples tested positive for PPRV antibodies in goats and sheep respectively which may be due to unequal sample sizes (fig 3). Similar studies conducted to investigate the seroprevalence of PPRV in goats and sheep have reported a high prevalence of PPR in goats and sheep [20,21]. In short, more goats and sheep in MD tested positive against PPRV antibodies compared to those in KD which supports studies conducted to investigate the presence of PPRV antibodies in sheep and goats that confirmed higher prevalence rates of PPRV in goats compared to sheep [22,23]. In similar studies carried out to investigate the presence of antibodies among sheep and goats in Indian and Pakistan revealed a high level of susceptibility of PPR in sheep which contradicts our findings [24,25]. Factors including management practices and system (traditional), type of virus strain in circulation, geographical differences, seasonal and climatic variations might have influenced the high seroprevalence of PPRV antibodies level in goats and sheep in the MD. The susceptibility of young goats and sheep to PPR disease was higher than that detected in adult male and female goats and sheep. $26.1 \%$ (93), 14.9\% (53) and 13.2\% (47) of all sera samples tested against PPR disease were positive for young, adult male and female goats respectively. Similar studies conducted by $[11,26]$ to investigate the presence of PPR antibodies in goats and sheep showed that young goats and sheep were highly susceptible compared to adult males and females.

Figure 5 portrayed information on the seroprevalence levels recorded among sampled goats and sheep in each of the study villages. The prevalence rate of antibody observed varies from one village to another, between and within species. In MD, Nyadehun, and Ngeiya recorded the highest positive cases for PPR. In Nyadehun, $16.7 \%, 15.9 \%$ and $9.8 \%$ of the goats investigated positive for PPR antibodies were young, adult males and females while in Ngeiya, $14.4 \%, 13.6 \%$, and $10.6 \%$ were seropositive in young, adult female and male goats respectively. Therefore, in Nyadehun and Ngeiya, young goats had the highest prevalence rate $(30.3 \%)$ followed by adult males $(27.3 \%)$ and females $(23.4 \%)$. 


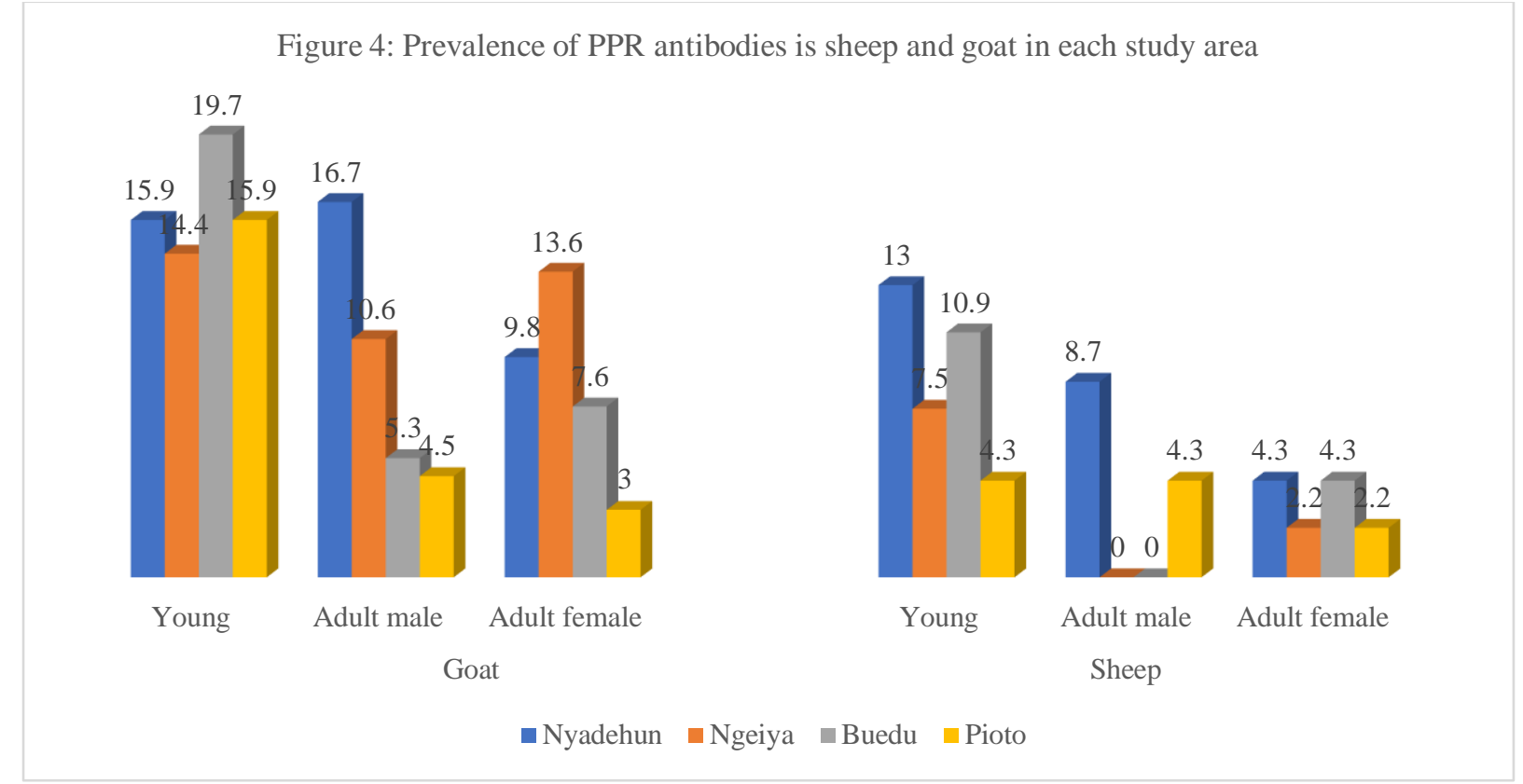

The molecular and antibody reports carried out by [24,27] have previously established that male goats were more susceptible to PPRV compared to females which disagree with this finding. $19.5 \%(13.0 \%=$ Nyadehun, $6.5 \%=$ Ngeiya $)$ of the sampled sheep showed positive

antibodies for PPR followed by adult male (Nyadehun $=8.7 \%)$ female $(6.5 \%: 4.3 \%=$ Nyadehun, $2.2 \%=$ Ngeiya) but no antibody was detected for adult sheep in Ngeiya.

In Buedu (KD), 19.7\%, 5.3\%, and 7.6\% of the tested young, adult male and female goats showed positive antibodies against PPR while in Pioto $15.9 \%, 4.5 \%$, and $3.0 \%$ of the samples collected for young, adult male and female goats were seropositive. Therefore, young goats $(35.6 \%)$ are severely affected by PPR compared to matured females (10.6\%) and males (9.8\%). Similarly, young sheep showed a higher antibody prevalence compared to the adult male and female. $15.2 \%$ $(10.9 \%=$ Buedu, $4.3 \%=$ Pioto $)$ of the young sheep, $4.3 \%$ adult male in Pioto and $6.5 \%(4.3 \%=$ Buedu, $2.2 \%=$ Pioto) adult female sheep showed positive antibodies for PPRV while adult male sheep in Buedu showed no antibody for PPR. The low rate of prevalence in sheep may be due to a high level of natural resistance.

\section{Conclusion and Recommendation}

Small ruminant production has great potential that could influence the livelihoods and the sociocultural and religious wellbeing of livestock farmers. Small ruminant production was mainly done at the traditional level that faced a series of production, management, and technical constraints. Major constraints including diseases, high mortality, poor extension and treatment services, neighbor conflict, theft, poor marketing, and lack of credit facility continue to paralyze small ruminant production in the study areas. Significant improvement is required in the area of animal healthcare services and husbandry practices, effective and efficient livestock extension services to educate and raise farmers' awareness of good management practices and biosecurity. 
The presence of PPR antibody has been established in both Moyamba and Kailahun districts and each of the four selected communities with an overall prevalence rate of $62.1 \%$. The result revealed that goats were highly susceptible to the disease $(54.2 \%)$ compared to sheep $(30.4 \%)$. Young animals showed the highest prevalence level than adult males and females for both goats and sheep. There is a need for annual vaccination to prevent, reduce the spread of and eliminate the disease. Further confirmatory investigations are needed to provide detailed epidemiological information about the disease regarding the strain of the virus, geographical distribution, socio-economic burden, seasonal occurrence, means of spreading, and management strategy.

\section{References}

[1] FAOSTAT, (2008). http://faostat.fao.org/default.aspx

[2] Ramsay G. and Leith A. Poverty alleviation and food security in Asia: role of livestock. Food Agricultural Organization of the United Nations Technical Report, FAO, (1999).

[3] Thornton, P. Livestock production: recent trends, future prospects. Philos, Trans R Sco Lond B Biol Sci., Vol. 365(1554), 2010, 2853-2867.

[4] Odoi, A. Gathuma, JM. Gachuiri, CK. Omore, A. Gitau, T. Wanyangu, SW. and Murage, E. (2000). Constraints to sheep and goat production in small holder mixed farms in Kenya's Central Highlands. Proceedings of the 9th international symposium on Veterinary Epidemiology and Economics, 227-229.

[5] Getachew, BF. Characterization of African goat production and productivities: The case of Ethiopia: A Review. Global Journal of Science Frontier Research: D Agriculture and Veterinary, vol. 16 (5), 2016, 2249-4626.

[6] Population and Housing Census, (2015). Statistics Sierra Leone. http://www.statistics.sl

[7] Balamurugan, V. Krishnamoorthy, P. Raju, DSN. Rajak, KK. Bhanuprakash, V. Pandey, AB. Gajendragad, MF. Prabhudas, K. and Rahman, H. Prevalence of Peste-des-petits-ruminants virus antibodies in cattle, buffaloes, sheep, goats in India. Virusesdisease, volume 25(1): 2014, 85-90.

[8] Abubakar, M. Mahapatra, M. Muniraju, M. Arshed, MJ. Khan, EH. Banyard, AC. Ali, Q. and Parida, S. Serological detection of antibodies to Peste des Petits Ruminants in large ruminants. Transboundary and Emerging Diseases, 64(1), 2017, 513-519.

[9] Emeli, T. Tebogo, K. Berg, M. Niwael, MM. Emanuel, SS, Jonas, JW. and Gerald, M. History and current status of peste des petits ruminant virus in Tanzania. Infection Ecology and Epidemiology, The One Health Journal, 2016.

[10] De Nardi, M. Lamin SSM. Batten, C. Oura, C. Di Nardo, A. and Rossi, D. First evidence of Peste des Petits Ruminants virus circulation in Algeria (Sahrawi Territories): Outbreak investigation and virus lineage identification. Transboundary and Emerging Diseases, vol. 59 (3), 2011, 214-22.

[11] Bello, AM. Lawah, JR. Dauda, J. Wakih, YM. Mshellia, ES. Ezema, KU. Balami, SY. Waziri, I. and Mani, AU. Research for Peste des Petits Ruminants virus antibodies in goats, sheep and gazelle from Bauchi and Gombe Staste, North Eastern Nigeria. Journal of Veterinary Medicine Science, 4(3), 2018, 161-171.

[12] Munir, M. Zohari, S. Suluku, R. LeBlanc, N. Kunu, S. Sankoh, FAR. Berg, M. Barrie, ML. and Stahl, K. Genetic characterization of Peste des Petits Ruminants virus, Sierra Leone. Emerging Infectious Diseases, Vol. 18, No. 1, 2012. www.cdc.gov/eid

[13] Banyard, AC. Parida, S. Batten, C. Oura, C. Kwiatek, O. and Libeau, G. Global distribution of peste des petits ruminant's virus and prospect for improved diagnosis and control. Journal of General Virology, 19, 2010, 2885-2897.

[14] Kamara, A. Koroma, BM. and Gogra, AB. Seasonal changes in vegetation and land use in LassaFever prone areas (Kenema and Kailahun Districts) in Eastern Sierra Leone. Natural Resources, vol. 6 (7), 2015, 450-456. DOI: 10.4236/nr.2015.67043 
[15] Jala, MK. Lamidi, OS. and Otaru, SM. Peri-Urban small ruminant production in Northern Guinea Savanna, Nigeria. Asian Journal of Animal and Veterinary Advances, vol. 3(3), 2008, 138-146.

[16] Fikru, S. and Omer, AA. Traditional small ruminant production in Awbare district of Ethiopian Somali Regional State. Journal of Animal Production Advances, vol. 5(6), 2015, 697-704.

[17] Tunji, IT. Small ruminant production and management techniques. https:/www.researchgate.net, 2015, DOI: 10.13140/RG.2.1.1817.8002

[18] Lefevre, PC. and Diallo, A. Peste des Petits Ruminant. Scientific and technical review; Review Scientific et Technique (OIE) 9, 1990, 951-965.

[19] Gopilo, A. Epidemiology of Peste des Petits Ruminants Virus in Ethiopia and Molecular Studies on Virulence, 2005. https://www.agritrop.cirad.fr

[20] Mehmood, A. Ali, Q. Gadahi, J.A. Malik, SA. Shah, SI. Detection of PPR virus antibodies in sheep and goat productions of the North West Frontier Province (NWFP) of Pakistan by competitive ELISA (cELISA). Vet World 2, 2009, 333-336.

[21] Getashew, G. Gedlu, M. Demeke, S. Ashebir, A. Mesfin, S. and Getnet, A. Participatory disease surveillance (PDS) of sheep and goat diseases in selected districts of Afar Regional State: Particular focus on PPR and sheep and goat pox disease. Ethiopian Veterinary Journal, 19 (1), 2015, 83-105

[22] Rahman, MZ. Haider, N. Gurley, ES. Ahmed, S. Osmani, MG. Hossain, MB. Islam, A. Khan, AS. Hossain, ME. Epstein, JH. Zeidner, N. and Rahman, M. Epidemiology and genetic characterization of PPV in Bangladesh. Journal of Veterinary Medicine and Science, Vol. 8(4), 2018, 161-171.

[23] Hota, A. Biswal, S. Sahoo, N. Rout, M. Chaudhary, D. Pandey, A. Dhanavelu, M. Seroprevalence of PPR among sheep and goats of different agro-climatic zones of Odisha. International Journal of Livestock Research, vol. 8(4), 2018, 2277-1964.

[24] Singh, RP. Saravanan, P. Sreenivasa, BP. Singh, RK. and Bandyopadhyay, SK. Prevalence and distribution of PPRV infection in small ruminants in India. Revue Scientifique et. Technique (International Office of Epizootics), vol. 23 (3), 2004, 807-819

[25] Munir, M. Siddique, M. Shehzad, A. Zohari, S. and Stahl, K. Seroprevalence of antibodies to PPR at various governmental livestock farms of Punjab, Pakinstan. Asian journal of Epidemiology, vol. 1(2), 2008, 82-90.

[26] Md. Raihan Nabi, Md. Shahadat Hossain, Sukumar Saha, Jahangir Alam, Md. Giasuddin. Molecular epidemiology of Peste des Petits Ruminants in goats. International Journal of Scientific and Technology Research Volume 7 (3), 2018, www.ijstr.org

[27] Sarker, S. \& Islam, MH. Prevalence and risk factor assessment of Peste des petits ruminants in goats in Rajshahi, Bangladesh. Veterinary World, 4(56), 2011, 986-549.

*Corresponding author.

E-mail address: amconteh@ njala.edu.s1 